\title{
HIGH SENSITIVE QUARTZ TEMPERATURE SENSORS
}

\author{
LOZAN Spassov \\ Georgi Nadjakov Institute of Solid State Physics, \\ Bulgarian Academy of Sciences, \\ 72, Tsarigradsko Shose, 1784 Sofia, Bulgaria, \\ e-mail:lozan_spassov@abv.bg
}

\begin{abstract}
This paper presents a new miniaturized design for thermo-sensitive quartz resonators with $\mathrm{yxl} /-31^{\circ} 30^{\prime}$ cut, and their possible application as attractive highly sensitive quartz temperature sensors. The design operates at $29.3 \mathrm{MHz}$ on fundamental frequency of $\mathrm{B}$ mode.

Keywords: piezoelectric, quartz resonator, sensor, temperature, measurement, control.
\end{abstract}

\section{INTRODUCTION}

Thermo-Sensitive Quartz Resonators (TSQR) have become very attractive as highly sensitive temperature sensors for various scientific and industrial needs, as they offer a number of advantages. They demonstrate good reproducibility, high sensitivity, long-term stability, and independence of electric, magnetic and radiation effects.

Quartz major advantage is its anisotropy. It facilitates the design of piezoelectric resonance devices, characterized by either very low or very high temperature-frequency dependence. The Temperature-Frequency Characteristics (TFC) of each resonator presents a polynomial of $\mathrm{n}^{\text {th }}$ order. It has the form of a straight line (LC cut), square (BT and CT cuts) or a cubic parabola (AT and SC cuts) [1]. On this basis, a series of different thermostable quartz resonators have been developed [2-3], which have been used for frequency control in telecommunications for more than 80 years now. And in the last 20-30 years they have served as time standards in microprocessor systems and consumer electronics.

Since 1962, a new approach to systematic research on frequency temperature sensitivity has been launched in order to create an attractive temperature sensor [4-5]. The first thermo-sensitive resonators with linear TFC in the range from minus $80^{\circ} \mathrm{C}$ to $230^{\circ} \mathrm{C}$ were developed by Hewlett-Packard

DOI: 10.7546/EngSci.LVIII.21.03.02 
researchers [6]. These resonators have been sold as temperature sensors for more than 25 years [7]. The main disadvantage of this type of sensors was the very high cost of the double-rotated cut of the quartz plate compared to the single-rotated Y-cut.

In 1987 L. Spassov and other colleagues found and proposed a new, singlerotated cut in quartz, Y-cut $\left(y x l / 31^{\circ} 30^{\prime}\right)$, which they named New Linear Coefficient (NLC) cut with a linear character of TFC in the temperature range from minus $30^{\circ} \mathrm{C}$ to $130^{\circ} \mathrm{C}$ [8-9].

The temperature sensitivity of the cut is $30 \mathrm{ppm} /{ }^{\circ} \mathrm{C}$, which corresponds to $1000 \mathrm{~Hz} /{ }^{\circ} \mathrm{C}$ for a quartz resonator at basic frequency of $29.3 \mathrm{MHz}$. The new cut has significant technological advantages over the LC cut used by HewlettPackard.

On the basis of this cut scientists in ISSP, BAS designed a highly sensitive Quartz Temperature Sensor (QTS) with linear TFC, which underwent several innovations in its development [10].

\section{PHYSICAL BASIS OF QUARTZ TEMPERATURE SENSORS}

For quartz resonators with a Y-cut and thickness-transverse vibration mode, the resonance frequency is determined by:

$$
f=\frac{1}{2 h} \sqrt{\frac{C_{66}^{\prime}}{\rho}},
$$

where $h$ is the thickness of the plate (the frequency determining value), and $\rho$ - the density of the quartz.

$$
C_{66}^{\prime}=C_{66} \cos ^{2} \theta+C_{44} \sin ^{2} \theta+C_{14} \sin 2 \theta,
$$

$C_{66}$ is the elastic constants, and $\theta$ is the angle between the $Z$ axis and the main surface of the piezoelectric element.

The temperature dependence of the frequency depends exclusively on the orientation of the plate towards the crystallographic axes of quartz. It can be represented by a $3^{\text {rd }}$ order polynomial [1]:

$$
f(t)=f_{0}\left[1+\sum_{n=1}^{3} T_{f}^{(n)}\left(t-t_{0}\right)^{n}\right],
$$

where $n=1,2,3$

$$
T_{f}^{(n)}=\left.\frac{1}{f_{0} n !} \frac{\partial^{n} f}{\partial t^{n}}\right|_{t=t_{0}}
$$

Engineering Sciences, LVIII, 2021, No. 3 
The temperature coefficient of frequency $T_{f}^{(n)}$ is the sum of the temperature coefficients of the first, second and third order frequency:

$$
T_{f}^{(n)}=T_{f}^{(1)}+T_{f}^{(2)}+T_{f}^{(3)} .
$$

Knowing the temperature coefficients for $C_{i j}$, an orientation of the plate was found in which the first-order temperature coefficient $T_{f}^{(1)}$ has a positive value, while the second-order temperature coefficients $T_{f}^{(2)}$ and third-order $T_{f}^{(3)}$ are equal, but with different signs. This leads to mutual compensation of $T_{f}^{(2)}$ and $T_{f}^{(3)}$ which significantly reduces the nonlinearity of TFC in a wide temperature interval.

The newly found orientation $\left(y x l /-31^{\circ} 30^{\prime}\right)$ Fig. 1, already known as NLCcut, was used for the design and production of a new quartz temperature sensor in the Laboratory of Acoustoelectronics at ISSP, BAS.

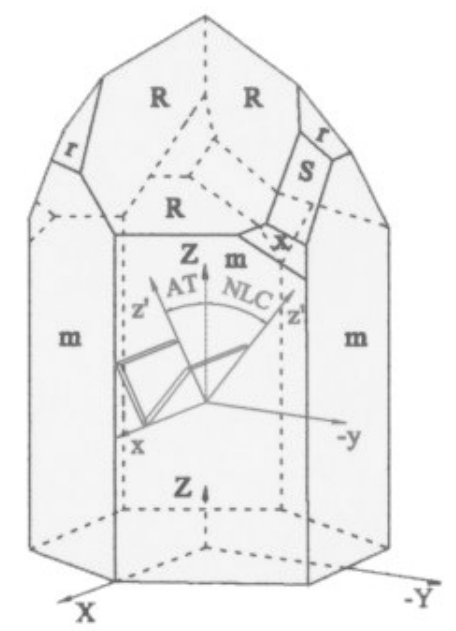

Fig. 1. Quartz crystal (AT and NLC cuts)

\section{RESEARCH AND TECHNOLOGICAL DEVELOPMENT OF QTS IN BULGARIA}

A miniature quartz temperature sensor was created with a $y x l /-31^{\circ} 30^{\prime}$ cut of the quartz plate (Fig. 2) at basic frequency of $29.3 \mathrm{MHz}$ [11]. The diameter of the quartz plate is $5 \mathrm{~mm}$ and the thickness is $82 \mu \mathrm{m}$. After polishing, silver electrodes with a diameter of $2.9 \mathrm{~mm}$ and thickness of $100 \mathrm{~nm}$ were 


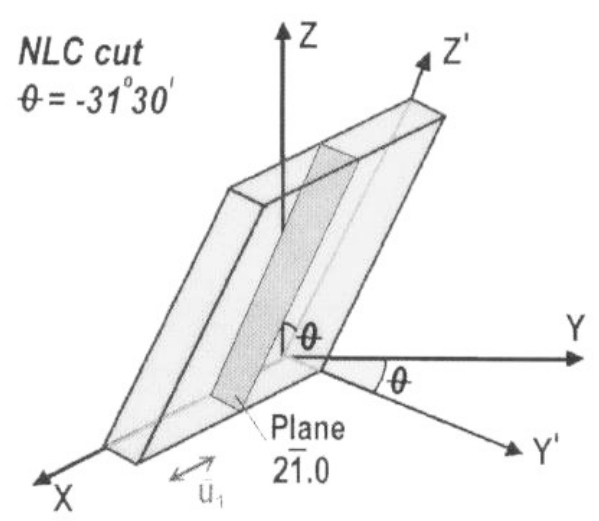

Fig. 2. Quartz plate NLC-cut
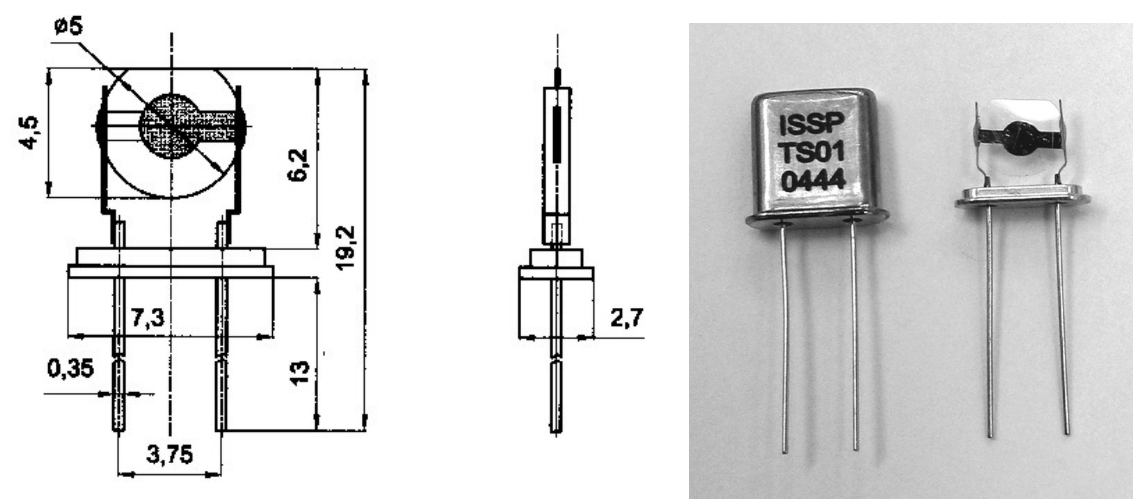

Fig. 3. QTS Design (mm)

deposited on the main surfaces of the plate. The piezoelectric elements were fixed and enclosed in a standard HC-49U corpus filled with dry nitrogen or helium depending on the temperature range for which they were intended to operate.

Figure 3 shows the design and dimensions of the QTS, as well as its exterior and interior. The TFC of the QTS in temperature range from minus $20^{\circ} \mathrm{C}$ to $120^{\circ} \mathrm{C}$ is shown in Fig. 4 .

The newly designed QTS was used in the prototype of a two-channel quartz thermometer QT-87, developed by the "Scientific Instrumentation" Department at BAS, Fig. 5 [12]. 


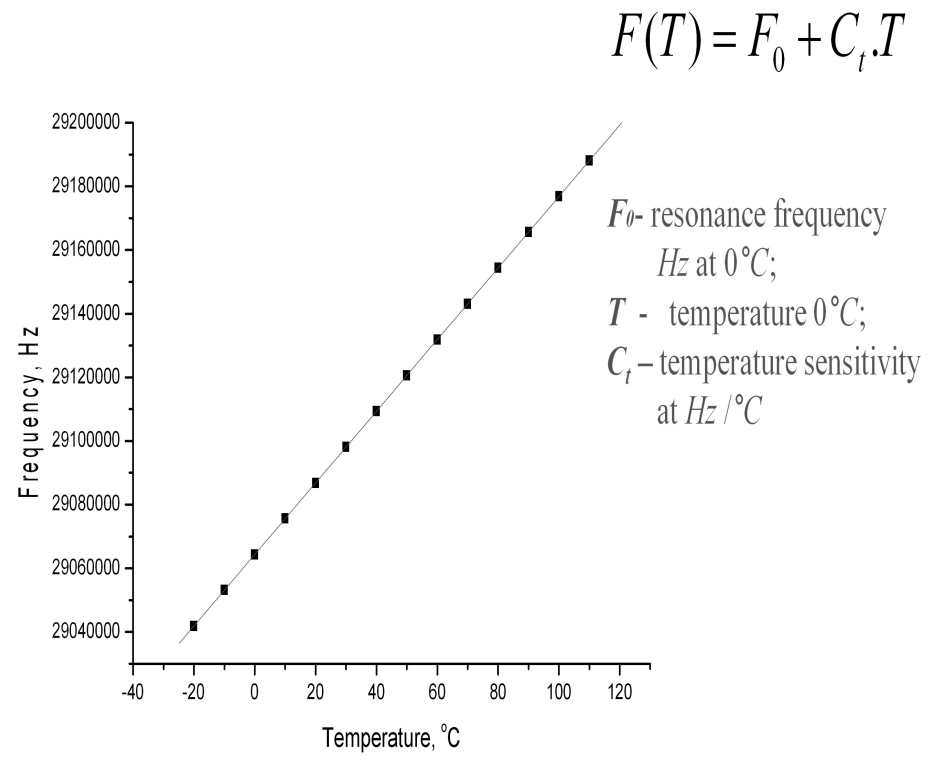

Fig. 4. TFC of the QTS

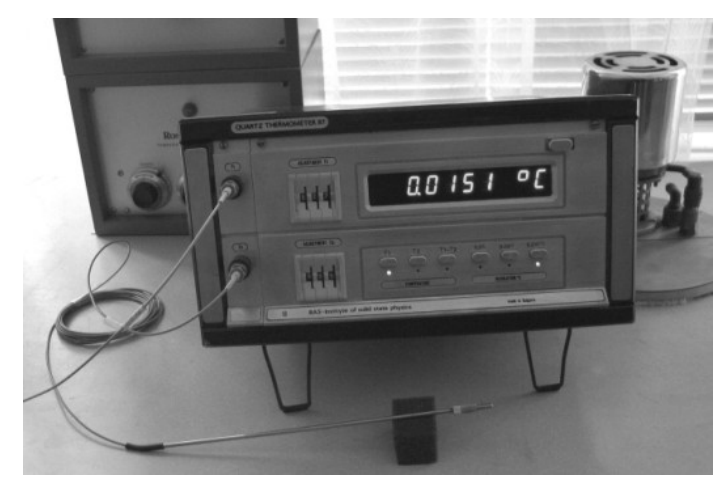

Fig. 5. Quartz thermometer QT- 87

The temperature sensitivity of the sensor $C_{t}$ in the whole temperature range is $1000 \mathrm{~Hz} /{ }^{\circ} \mathrm{C}$, which allows for temperature changes less than $0.001{ }^{\circ} \mathrm{C}$ to be registered.

Under a contract funded by the Joint Institute for Nuclear Research (JINR) in Dubna, Russia, low temperature studies have been underway for several years, Fig. 6. They were focused on disturbances that occurred in the TFC of QTS at certain cryogenic temperatures. 


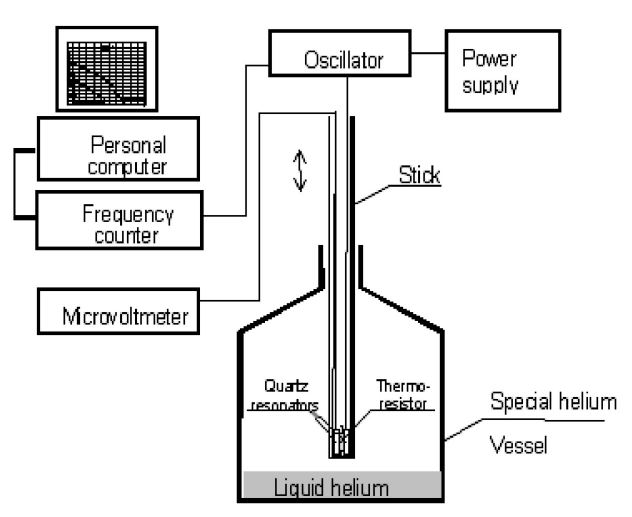

Fig. 6. Block diagram for temperature studies at cryogenic temperatures

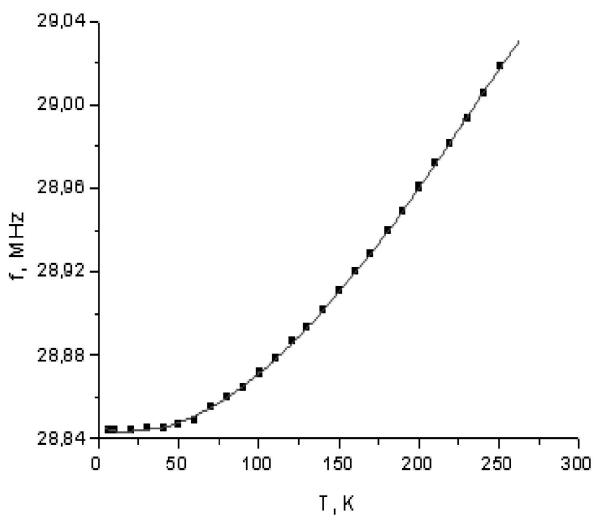

Fig. 7. TFC of QTS $(4.2 \mathrm{~K}-300 \mathrm{~K})$

Based on the obtained results [13], we optimized the quartz piezoelectric element, which provided a monotone increasing function of the temperaturefrequency dependence without interruption or to jumping on another frequency, Fig. 7 [14].

In JINR, Dubna, Russia the QTS was tested in conditions of strong electric and magnetic fields (up to 5 Tesla) [15] and radiation effects [16].

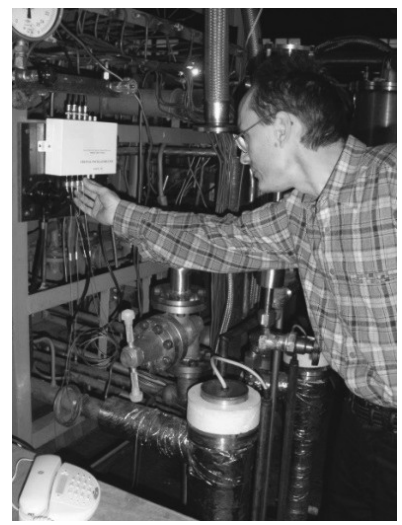

(a)

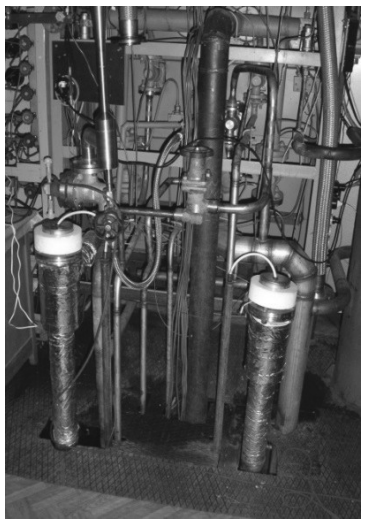

(b)

Fig. 8. (a) Application of the QTS for temperature control;

(b) measurement of helium flow rate in the cryogenic complex of JINR, Dubna, Russia 
After successfully passing the tests, the QTS was included in the cryogenic complex of the nuclear accelerator "Nuclotron" for temperature control, Fig. 8 (a), and measurement of helium flow rate, Fig. 8(b). After these tests, the QTS expanded its operating temperature range from $4.2 \mathrm{~K}$ to $420 \mathrm{~K}$.

\section{METROLOGICAL CHARACTERISTICS}

- Temperature range $-4.2 \mathrm{~K}$ to $420 \mathrm{~K}$, Fig. 9 [17]

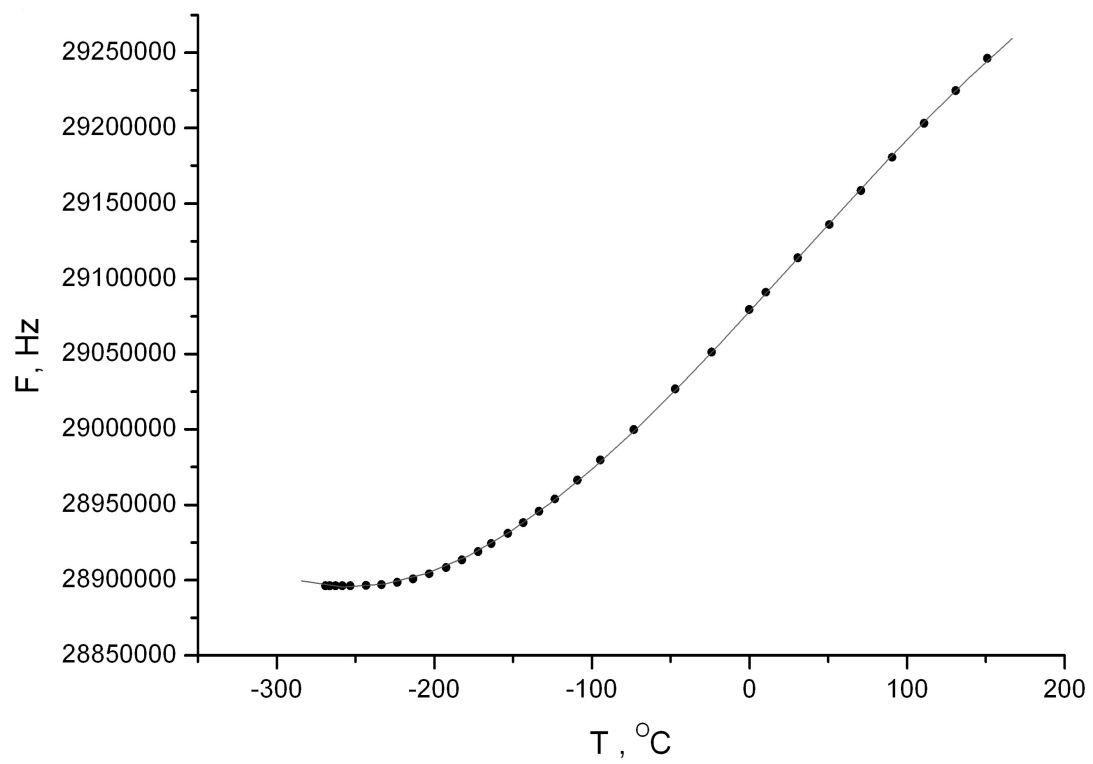

Fig. 9. TFC of QTS in the range from $4.2 \mathrm{~K}$ to $300 \mathrm{~K}$ (minus $273^{\circ} \mathrm{C}$ to $200^{\circ} \mathrm{C}$ )

- Temperature sensitivity $-C_{t}=\Delta f / \Delta T$

Minimal temperature fluctuations, which can be registered [18]:

at $4.2 \mathrm{~K}-\Delta T \min =50 \mathrm{mK}$;

at $20 \mathrm{~K}-\Delta T \min =8 \mathrm{mK}$;

at $130 \mathrm{~K}-\Delta T \min =0.12 \mathrm{mK}$;

at $300 \mathrm{~K}-\Delta T \min =0.085 \mathrm{mK}$.

- Time constant (response time) Fig. 10 and cyclic change Fig. 11 [17]

- Long-term stability of QTS [18]

The long-term stability of the resonance frequency for 1400 days is within $2 \times 10^{-6}$ (Fig. 12) [18], which corresponds to the temperature stability of the sensor $0.005^{\circ} \mathrm{C}$ (Fig. 13). 


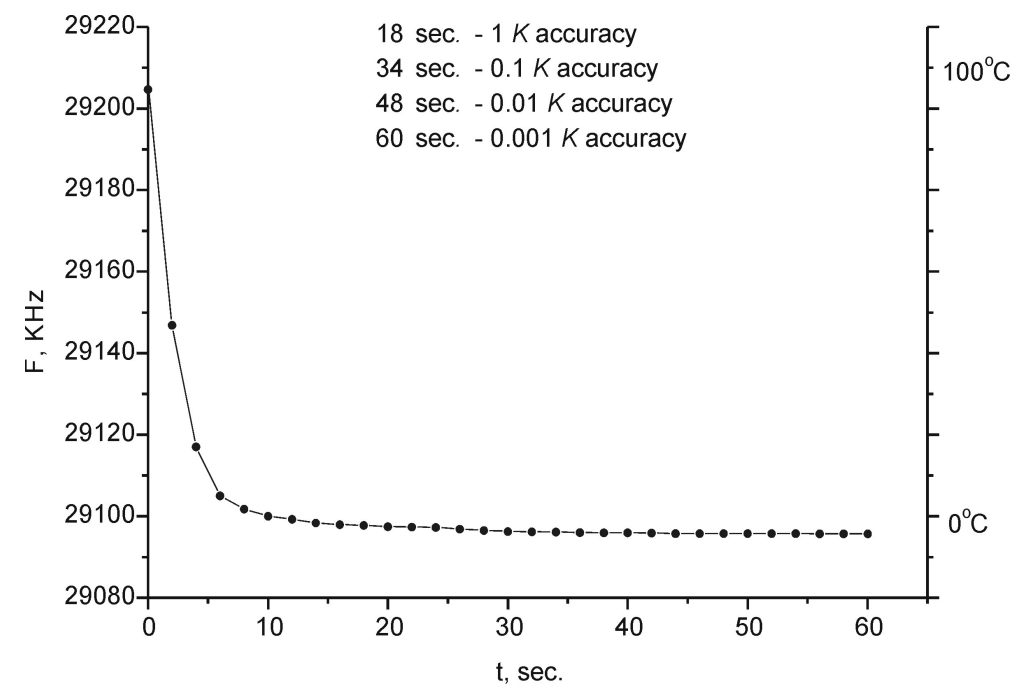

Fig. 10. Time constant of QTS

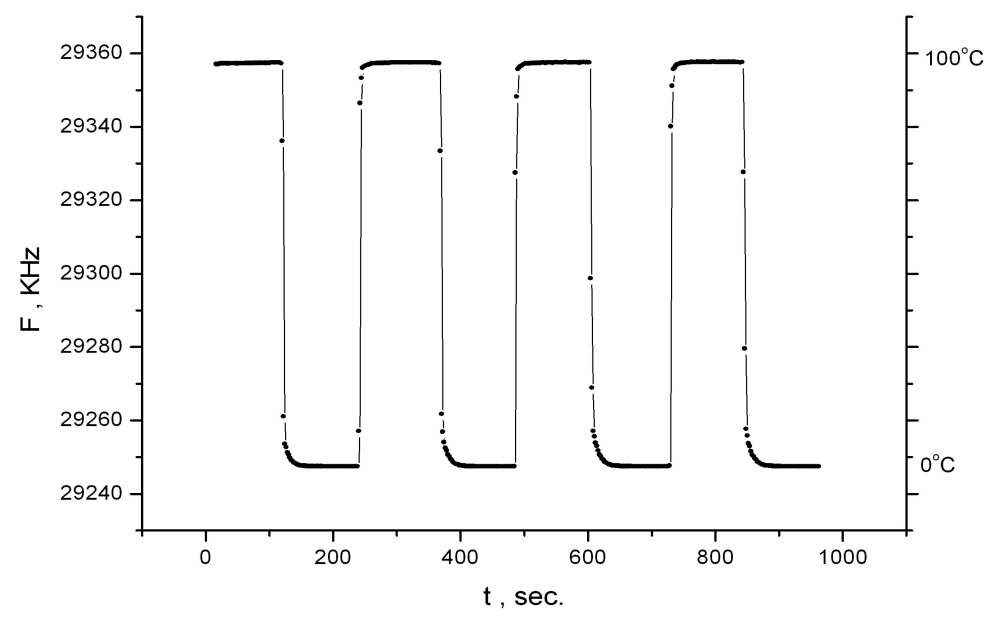

Fig. 11. Time constant at cyclic change of temperature from $100{ }^{\circ} \mathrm{C}$ to $0{ }^{\circ} \mathrm{C}$ and vice versa

The results of the conducted tests guarantee reliable operation of the QTS for more than 10-15 years with no need for additional calibration. 


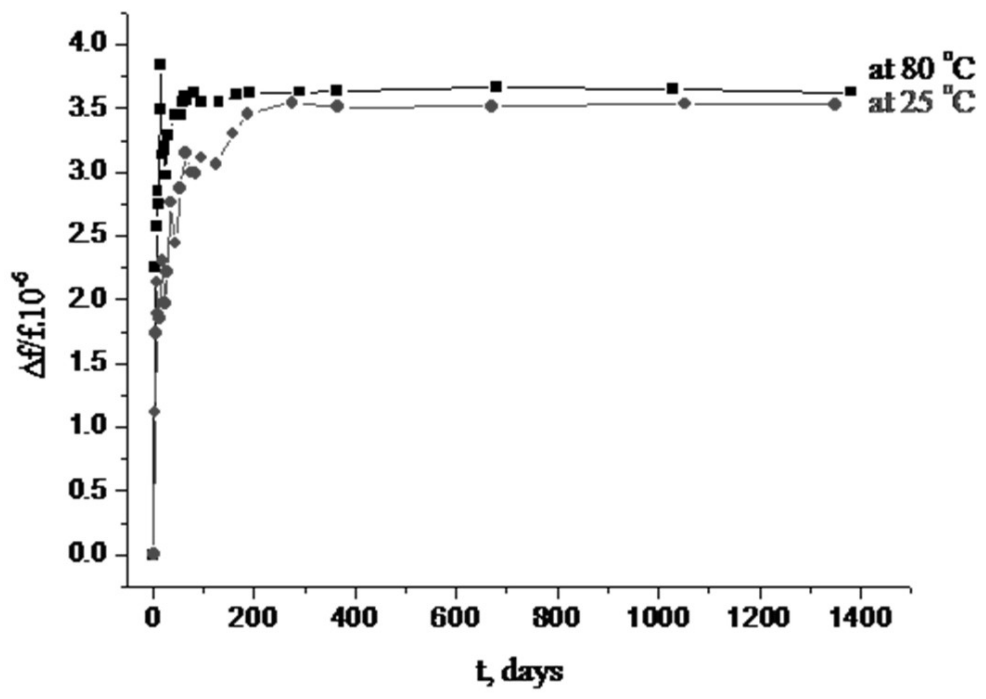

Fig. 12. Long-term stability of the resonance frequency of QTS

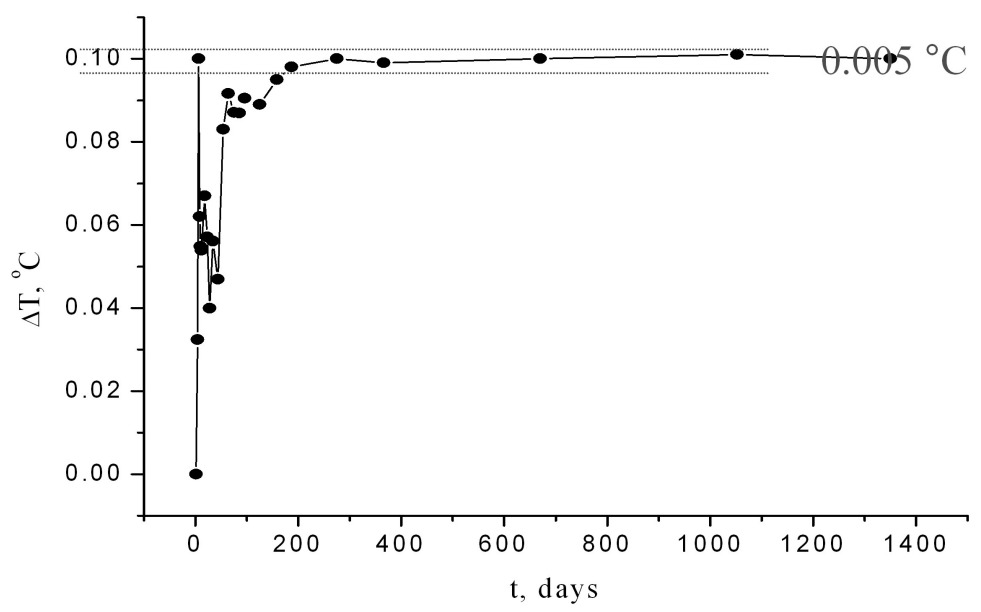

Fig. 13. QTS stability expressed in change of temperature 


\section{ADVANTAGES OF QUARTZ TEMPERATURE SENSORS}

There are some important advantages of QTS over temperature sensors, created on other physical principles, operating in the temperature range from $4.2 \mathrm{~K}$ to $420 \mathrm{~K}$ :

- High sensitivity (up to $0.0002{ }^{\circ} \mathrm{C}$ );

- High absolute accuracy (up to $0.005^{\circ} \mathrm{C}$ ) $(*)$;

- Wide dynamic range including cryogenic temperatures $(4.2 \mathrm{~K} \div 420 \mathrm{~K}$ );

- Independence from strong electric, magnetic and radiation fields;

- Output signal, which is very convenient for digital information processing;

- Long-term stability, guaranteeing reliable operation of the sensors without additional calibration;

(*) Depending on the accuracy of the calibration system.

Findings and results of a 20-year long research on quartz temperature sensors and their applications have been presented at more than 25 national and international scientific forums. They are documented in more than 40 publications, 2 patents, 2 doctoral dissertations and 1 dissertation for the degree "Doctor of physical sciences".

Constructive and technological documentation for industrial production of QTS has been compiled and offered for implementation to a small enterprise.

\section{CONCLUSIONS}

The advantages of QTS were demonstrated in the newly designed prototypes of highly sensitive quartz thermometers QT-87, used in the temperature control systems of cryogenic liquefaction systems in JINR Dubna, Russia, as well as in cryogenic installations for lyophilization of blood plasma and sterile food products. However, they are not yet widely used. There are several reasons for that:

- In terms of metrological characteristics quartz temperature sensors are still significantly ahead of modern market needs. Even nowadays markets for temperature measuring instruments demand accuracy mostly within the range of $1{ }^{\circ} \mathrm{C}$ or a few tenths of a degree. This demand is met by widely used, relatively inexpensive temperature sensors with analog output, based on different physical principles. In this case the market does not stimulate, but rather delays the long-term technological development of temperature sensors.

- Large companies for temperature and heat meters have invested substantial human and financial resources for the development and production of 
devices, based on temperature sensors with analog output. The market is currently satisfied and manufacturers are not that interested in developing new thermometers based on sensors with frequency output, which require additional funding. Such a task is particularly difficult for small companies, which cannot accomplish it without external financing.

For more than 80 years, quartz thermostable resonators have acted as a stabilizing element for frequency control in all telecommunications appliances. For more than 40 years, they have been increasingly recognized as an indispensable time standard in microprocessor and consumer electronics. As early as the 1980s, initially quite timidly and then rather quickly, they established themselves as precise and reliable timekeepers, displacing traditional mechanical watches.

The time is not far off when quartz thermo-sensitive resonators, much like their predecessors, will find their application as attractive, highly sensitive and reliable sensors for the production of devices for precise temperature control and measurement.

\section{REFERENCES}

[1] R. Bechman, A. D. Balato, and T. J. Lukaszek, Higher Order Temperature Coefficients of the Elastic Stiffness and Compliance of Alfa-quartz, in: Proceedings of IRE, 1962, 50, 1812-1822.

[2] A. G. Smagin and M. Y. Yaroslavski, Piezoelectric Quartz and Quartz Resonators, Energy, Moscow (1970) 488 (in Russian).

[3] P. G. Pozdniakov, Handbook of Quartz Resonators, Sviaz, Moscow (1978) 4954 (in Russian).

[4] W. H. Wide and L. J. Slutsky, Quartz Crystal Thermometer, Review of Scientific Instruments (1962) 33 212-213.

[5] W. L. Smith and W. J. Spencer, Quartz Crystal Thermometer for Measuring Temperature Deviations in $10^{-3}$ to $10^{-6}{ }^{\circ} \mathrm{C}$ Range, Review of Scientific Instruments (1963) 34 268-270.

[6] D. L. Hammoud and A. Benjaminson, Linear Quartz Thermometer, Instrumentation Control Systems (1962) 38 115-119.

[7] Quartz Thermometer 2804A, Hewlett-Packard catalog.

[8] M. Borissov, L. Spassov, et al. Quartz Resonator, Bulgarian Patent No. 81377 (1987).

[9] M. Borissov, L. Spassov, E. Yossifov, A. Balabanova, and E. Radeva, New Cut of Quartz Resonators with a Linear Temperature Frequency Characteristic, Electronics Letters (1987) 23 (4) 169-171. 
[10] L. Spassov, Piezoelectric Quartz Resonators as Highly Sensitive Temperature Sensors, Sensors and Actuators A (1992) 30 67-72.

[11] L. Spassov, E. Yossiffov, V. Georgiev, and L. Vergov, A Rotated Y-cut Quartz Resonator with a Linear Temperature-Frequency Characteristic, Sensors and Actuators, A58 (1997) 185-189.

[12] M. Borissov, L. Spassov, A. Balabanova, N. Nikolova, M. Yanakiev AND L. Vergov, Highly Sensitive Quartz Thermometer QT-87, Journal of Standardization, Certification and Metrology (1991) 4 48-50 (in Bulgarian).

[13] L. Spassov, V. Georgiev, L. Vergov, N. Vladimirova, V. Drobin, and N. Agapov, Some Investigations on Thermo-Sensitive Quartz Resonators at Cryogenic Temperature, in: Proceedings of EUROSENSORS'X, September 811, 1996, Leuven, Belgium, pp. 1421-1424.

[14] B. Dulmet, R. Bourquin, L. Spassov, V. Georgiev, and R. Velcheva, Investigation of Activity-Dips in Thermo-Sensitive Quartz Resonators at Cryogenic Temperature, in: Proceedings of the $15^{\text {th }}$ EFTF, March 6-8, 2001, Neuchatel, Switzerland, pp. 79-83.

[15] R. Velcheva, L. Spassov, Yu. Filipov, V. Miklayev, and V. G. ShabraTOV, Influence of Magnetic Field on the Frequency Response of the ThermoSensitive Quartz Resonators, in: Proceedings of Relativistic Nuclear Physics from Hundreds of MeV to TeV, Varna, 2001, pp. 155-161.

[16] R. Velcheva, L. Spassov, Yu. Filipov, V. Miklayev, and E. Kulagin, Radiation Resistance of Thermo-Sensitive Quartz Crystal Resonators, in: Proceedings of the $16^{\text {th }}$ EFTF, St. Petersburg, Russia, March 2002, pp. D048 to D050.

[17] L. Spassov, R. Velcheva, Ts. Yordanov, L. Vergov, B. Dulmet, and R. Bourquin, Investigations of Thermo-Sensitive Quartz Resonators NLC-cut at Cryogenic Temperatures, in: $16^{\text {th }}$ European Frequency and Time Forum, St. Petersburg, Russia, 2002.

[18] L. Spassov, V. Gadjanova, R. Velcheva, and B. Dulmet, Short and LongTerm Stability of Resonant Quartz Temperature Sensors, IEEE Transactions on Ultrasonics, Ferroelectrics, and Frequency Control (2008) 55 (7) 1626-1633.

Received April 26, 2021

Engineering Sciences, LVIII, 2021, No. 3 